Department of

Medical Genetics,

Belfast City Hospital,

Lisburn Road, Belfast

BT9 7AB, Northern

Ireland

A D Irvine

F J Stewart

NC Nevin

Department of

Dermatology, Royal

Group of Hospitals,

Belfast BT12 6BA,

Northern Ireland

O M Dolan

E A Bingham

Sir George E Clark

Metabolic Unit, Royal

Group of Hospitals,

Belfast BT12 6BA,

Northern Ireland

D R Hadden

Correspondence to: Dr Irvine.

Received 14 May 1996 Revised version accepted fo publication 28 June 1996

\title{
An autosomal dominant syndrome of acromegaloid facial appearance and generalised hypertrichosis terminalis
}

\author{
Alan D Irvine, Olivia M Dolan, David R Hadden, Fiona J Stewart, E Ann Bingham, \\ Norman C Nevin
}

\begin{abstract}
We report a family in which a phenotype of acromegaloid facial appearance (AFA) and generalised hypertrichosis terminalis segregates through three generations. Congenital hypertrichosis terminalis and AFA have been previously reported as independent autosomal dominant traits. This is the first report to delineate an autosomal dominant transmission of the combined phenotype.

(f Med Genet 1996;33:972-974)
\end{abstract}

Key words: terminal hypertrichosis; acromegaloid facies; autosomal dominant.

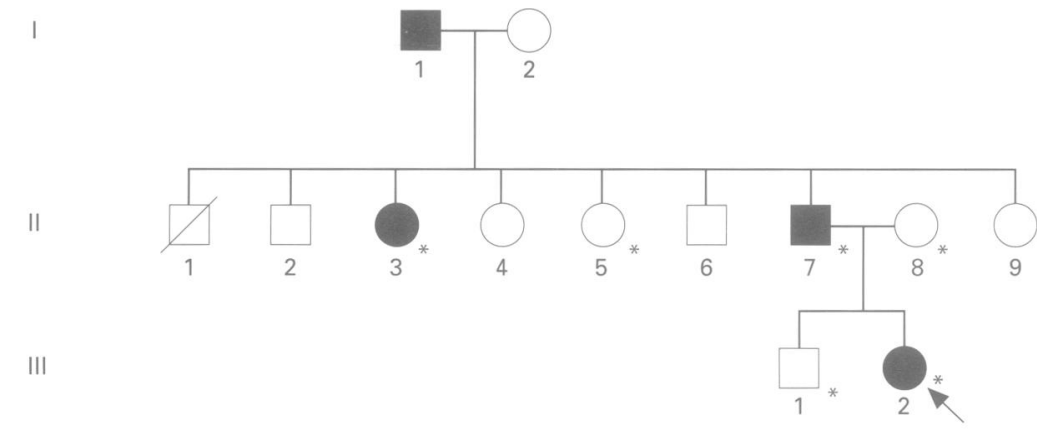

Figure 1 Family pedigree. *Personally examined by the authors.
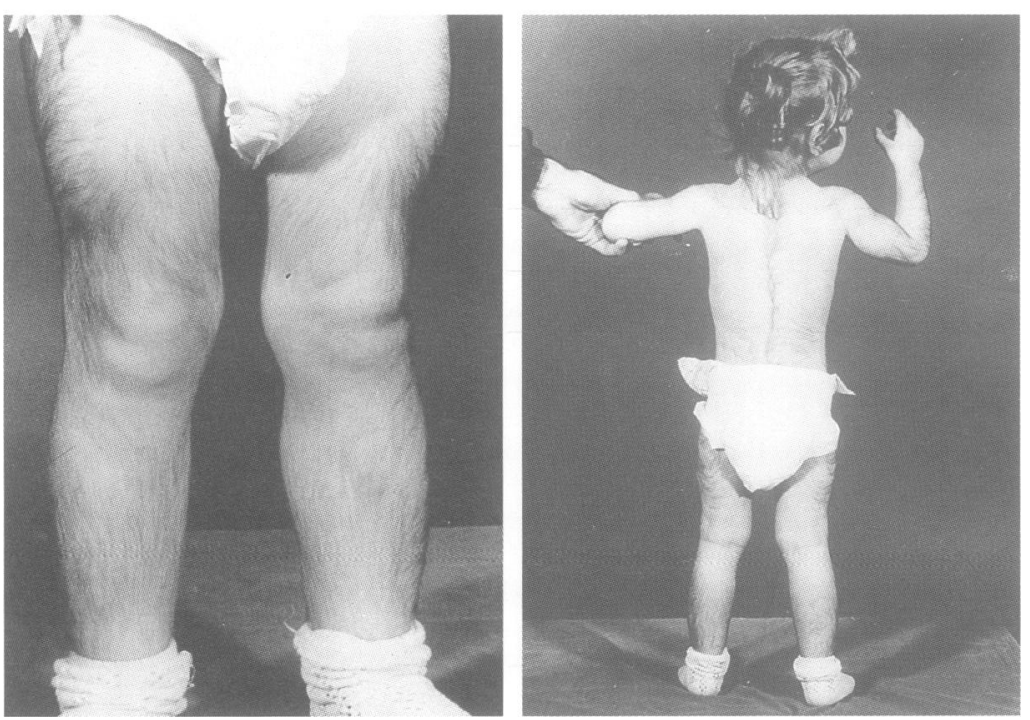

Figure 2 Proband aged 2 years: marked generalised terminal hypertrichosis. (All photographs reproduced with permission.)
A family with four affected subjects in three generations is reported. Affected subjects show a characteristic acromegaloid facial appearance (AFA) and generalised hypertrichosis terminalis. The syndrome is inherited as an autosomal dominant trait and appears to be fully penetrant. Acromegaloid facial appearance and hypertrichosis terminalis have been described in association with thickened oral mucosa and gingival hyperplasia. ${ }^{12}$ Affected patients in our family did not have intraoral lesions. The syndrome in our family appears to be discrete from the acromegaloid facial appearance syndrome, ${ }^{3}$ Gorlin-Chaudhry-Moss syndrome, ${ }^{4}$ and pachydermoperostosis. ${ }^{5}$

\section{Case report}

The proband (fig 1, III.2), a term product of healthy, non-consanguineous parents, was initially seen aged 2 years, when a dermatological opinion was sought regarding striking generalised terminal hypertrichosis (fig 2). The hypertrichosis was first noted shortly after birth and had become progressively more marked. There was a coarsening of the facial appearance with broadening of the nose and swelling of the lower lip (fig 3). The intraoral mucosa and the tongue were normal. General physical examination, including the genitalia, was normal; height and weight were just below the 97th centiles. Endocrine assessment, including mucopolysaccharide analysis, was normal and radiological survey was normal, with bone age commensurate with chronological age. There was no digital "tufting".

\section{Family history}

The pedigree is shown in fig 1 . The syndrome is inherited as an autosomal dominant trait with both sexes affected and male to male transmission. One affected subject (fig 1, I.1) was not examined by the authors; the affected status was assigned following a collaborative history from the affected offspring. In generation II, the proband's paternal aunt (fig 1, II.3) and father (fig 1, II.7) showed an acromegaloid facial appearance (figs 4 and 5) and generalised terminal hypertrichosis. Facial hypertrichosis (fig 4) was seen in the paternal aunt. Physical examination was normal and the intraoral mucosa and the gingivae were normal in both patients. Both II. 3 and II.7 were referred to the Endocrinology Department because of a clinical suspicion of acromegaly. 


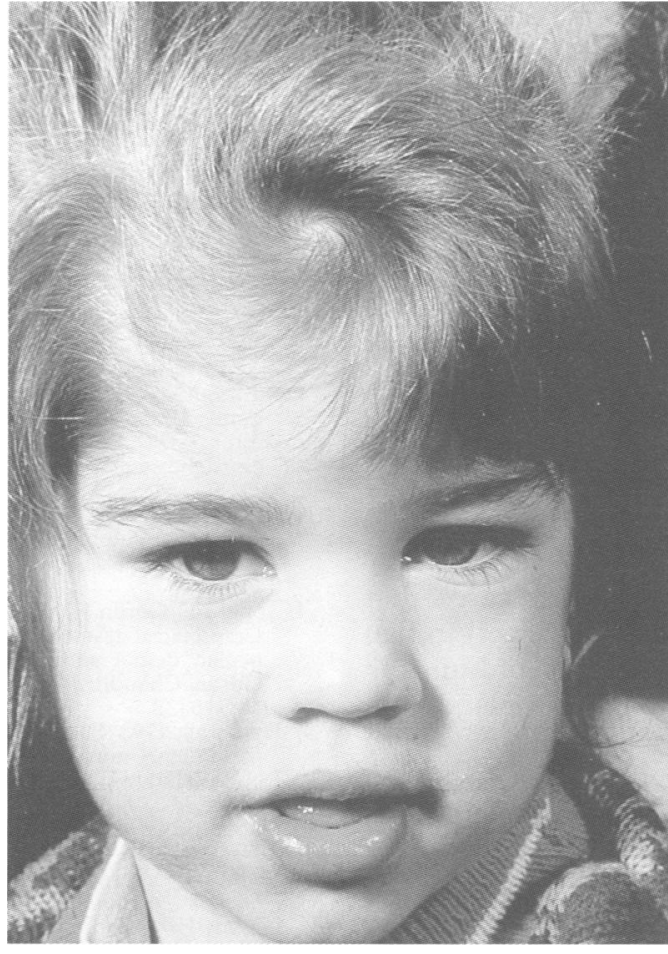

Figure 3 Proband aged 2 years: coarsening of facial features and thickening of the lower lip.

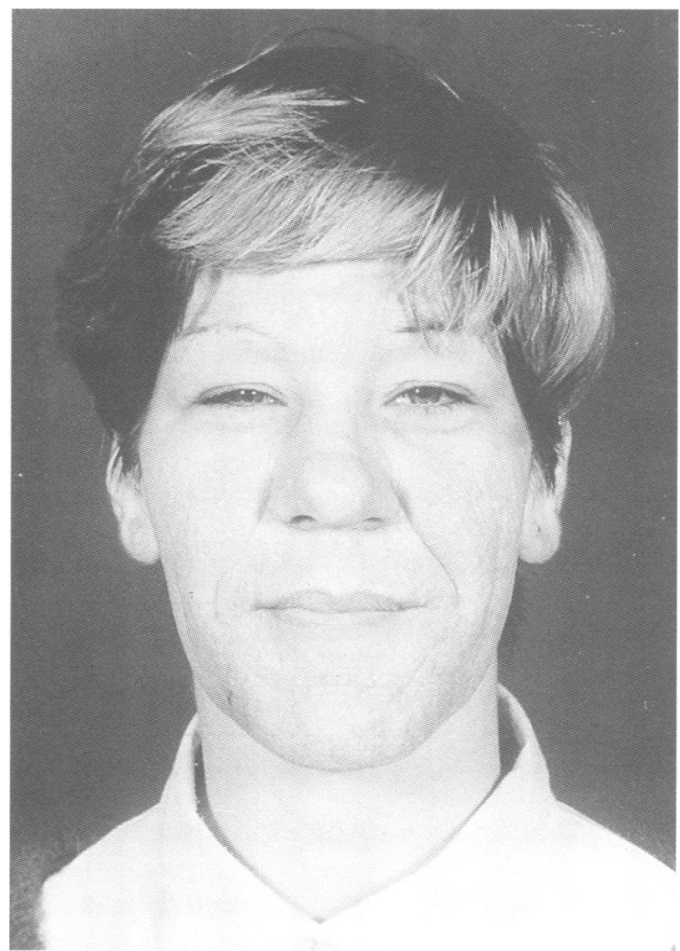

Figure 4 The paternal aunt (patient II.3, fig 1): acromegaloid facial appearance and facial hypertrichosis.

The endocrine opinion did not support this diagnosis; there were no typical changes of excess growth hormone secretion, such as enlargement of jaw or tongue, and hand volumes were normal. II.3 had initial investigations which showed persistently high levels of serum growth hormone on a number of tests (oral glucose tolerance, insulin hypoglycaemia), and she had been treated briefly on the basis of these results. Subsequent tests remained fully

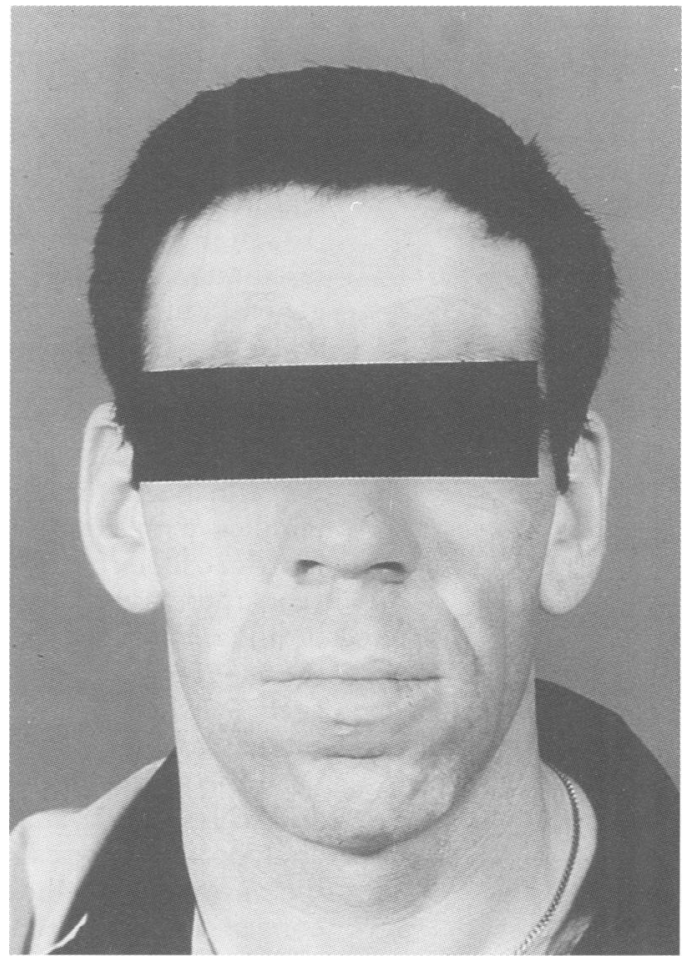

Figure 5 The proband's father (patient II.7, fig 1), aged 28: marked facial coarsening with "acromegaloid" appearance.

normal and no subsequent treatment has been given. The most recent measurement (1994) in II. 3 are growth hormone $0.5 \mathrm{mU} / \mathrm{l}$, IGF1 $22.7 \mathrm{nmol} / 1$, and in II.7 growth hormone $1.5 \mathrm{mU} / 1$, IGF1 $14.3 \mathrm{nmol} / 1$, all of which are within a normal adult range. There was no evidence of insulin resistance, and serum insulin levels during oral glucose tolerance tests in both were normal. The father of the proband (fig 1, II.7) had a history of recurrent idiopathic cardiac effusions, necessitating pericardial fenestration. No other family member had pericardial effusions.

\section{Discussion}

This family has four affected members in three generations, confirming an autosomal dominant pattern of inheritance. The most striking features of the affected phenotype are an "acromegaloid" facial appearance and generalised hypertrichosis terminalis. All affected subjects had normal intraoral mucosa and gingivae. An acromegaloid facial appearance is associated with several autosomal dominant conditions, such as pachydermoperostosis ${ }^{5}$ and Ascher syndrome. ${ }^{6}$ Our family does not have any other clinical features suggestive of these disorders nor, to our knowledge, has hypertrichosis been a feature of these conditions. Our family has hypertrichosis and a coarsened facial appearance in common with the GorlinChaudray-Moss syndrome (GCM). They lack, however, the characteristic stocky build, genital hypoplasia, phalangeal hypoplasia, conductive hearing loss, and midface hypoplasia considered characteristic of GCM. ${ }^{4}$ The acromegaloid facial appearance (AFA) syndrome (MIM No $102150^{7}$ ) described by Hughes et 
$a^{\beta}$ and which was later reported in a second family ${ }^{8}$ was considered as a possible diagnosis. Our family lacked the intraoral mucosal hypertrophy seen in AFA syndrome. In addition, generalised hypertrichosis terminalis was not a feature in either of the two AFA families.

Congenital hypertrichosis has long held a fascination for both medical authors and the general public. Cockayne ${ }^{9}$ proposed two main divisions: hypertrichosis lanuginosa (HL) or dog faced type and hypertrichosis terminalis or simian faced type, ${ }^{9}$ a classification adhered to by subsequent authors. ${ }^{10}$ In an exhaustive review, Felgenhauer ${ }^{11}$ found fewer than 40 discrete families with congenital HL. Congenital hypertrichosis terminalis is even rarer; for many years there were only two published cases, that of Julia Pastrana, a Mexican Digger Indian (1834-1860) and of Krao, a native of Bangkok aged 7 who was exhibited in England and France in $1883 .{ }^{12}$ Julia Pastrana's diagnosis has been the source of debate. Recently Bondeson and Miles, ${ }^{13}$ after an extensive study, including analysis of historical evidence and $x$ rays of the mummy, concluded that the diagnosis was congenital generalised hypertrichosis terminalis with gingival hyperplasia ${ }^{13}$ (MIM No $135400^{7}$ ). This condition was described as early as $1886 .^{14}$ There is also some evidence to suggest that Krao had this condition ${ }^{1315}$ (for a major review see Witkop ${ }^{16}$ ). There are two reports of cases of congenital generalised hypertrichosis terminalis with gingival hyperplasia which showed an "acromegaloid" facial appearance. ${ }^{12}$ Thus a spectrum of severity of this condition appears to exist, ranging from mild gingival hyperplasia to generalised hypertrichosis, gingival hyperplasia, and facial deformity.

The diagnosis in our family raises several possibilities. The phenotype may represent a variant of the congenital hypertrichosis/gingival hyperplasia syndrome, although this seems un- likely in view of the entirely normal oral mucosa and gingivae. It is also possible that our family is a variant of the AFA syndrome, but again terminal hypertrichosis and intraoral pathology is absent.

We consider that our family represents a new syndrome, discrete from AFA syndrome ${ }^{3}$ and congenital hypertrichosis/gingival hyperplasia. $^{12}$

1 Rushton MA. Hereditary or idiopathic hyperplasia of the gums. Dental Practit 1957;7:136-46.

2 Vontobel F. Idiopathic gingival hyperplasia and hypertrichosis associated with acromegaloid features. Helv Paediatr Acta 1973;28:401-11.

3 Hughes HE, McAlpine PJ, Cox DW, Philipps SA. An autosomal dominant syndrome with "acromegaloid" features and thickened oral mucosa. F Med Genet 1985;22

4 Ippel PF, Gorlin RJ, Lenz W, VanDoorne JM, Bijlsma JB Craniofacial dysostosis, hypertrichosis, genital hypoplasia, ocular, dental and digital defects. Confirmation of the Gorlin-Chaudhry-Moss syndrome. Am F Med Genet 1992; 44:518-22.

5 Hambrick GW, Carter DM. Pachydermoperiostosis (idiopathic clubbing and periostosis): genetic and physiologic considerations. N Engl f Med 1965;272;923-31.

6 Barnett ML, Bosshardt LL, Morgan AF. Double lip and double lip with bepharochalasis (Ascher's syndrome). Oral Surg 1972;34:727-33.

7 McKusick VA. Mendelian inheritance in man: a catalog of human genes and genetic disorders. Vol 1. Baltimore: The Johns Hopkins University Press, 1994.

8 Dallapicolla B, Zelante L, Accadia L, Mingarelli R. Acromegaloid facial appearance (AFA) syndrome: report of a second family. $\mathcal{F}$ Med Genet 1992;29:419-22.

9 Cockayne AA. Inherited abnormalities of the skin and its appendages. London: Oxford University Press, 1993:2459 .

10 Ebling FJG, Dawber R, Rook A. The hair. In: Rook A Wilkinson DS, Ebling FJG, Champion RH, Burton JL eds. Textbook of dermatology. Vol 3. Oxford: Blackwel Scientific Publications, 1986:1959.

11 Felgenhauer WR. Hypertrichosis lanuginosa universalis. $f$ Genet Hum 1969;17:1-44.

12 Gould GM, Pyle WL. Anomalies and curiosities of medicine. London: Sydenham, 1956:231.

13 Bondeson J, Miles AEW. Julia Pastrana, the nondescript: an example of congenital, generalised hypertrichosis terminalis with gingival hyperplasia. Am $\mathcal{f}$ Med Genet 1993 47:198-212.

14 Parreidt J. Uber die Bezahnung bei Menschen mit abnormer Behaarung. Deutsche Monatsschr Zahnheilkd 1886;4:41-54.

15 Bartels $M$. Uber den Affemenschen und den $\mathrm{Ba}-$ renmenschen. Z Ethnol 1884;16:106-13.

16 Witkop CJ. Heterogeneity in gingival fibromatosis. Birth Defects 1971;7:210-21. 